\title{
PARASITE BIOLOGY
}

$\mathrm{T}$ HE third spring meeting of the Parasitology Group of the Institute of Biology was held at Wills Hall, Bristol, during April 11-13. The meetings were well attended, and a number of visitors from overseas were present. There can be no doubt that this annual meeting held at a provincial centre has become established firmly in the activities of the Group. An important item in the programme was the address by an invited speaker. This item was introduced last year at Liverpool when Prof. T. H. Davey took as his subject "Parasites as Enemies and Allies". It proved a very useful focus of interest, and this year Prof. C. Read was invited to speak. He gave as his title "The Host-Parasite Interface: Molecular Basis of Parasitism". Prof. Read is professor of biology in the Rice Institute, Houston, Texas, and is at present on sabbatical leave working at the Molteno Institute, Cambridge. He began by discussing parasitism as part of a broad definition of 'symbiosis' considered as a function of the intensity of the field of association established between organisms, and of the internal and external resistances surmounted in its establishment. The parasite comes to depend on the host for the maintenance of homeostasis, and the regulation of homeostasis of a parasite intimately involves a region in space and time which can be designated 'the hostparasite interface'. The host, however, is not $\mathbf{a}_{\mathbf{b}}$ passive environment, and interaction plays an impor. tant part in this concept of parasitism. The primary exchanges at the interface are chemical, and Prof. Read proceeded to discuss examples of these obtained from work with which he has been associated in the United States. He concluded by suggesting how hostparasite specificity and pathology might be discussed in terms of chemical exchanges.

The general sessions were devoted to a series of 19 short papers, each being followed by a period of discussion. This type of meeting is useful because it gives an indication of the fields in which the main research is taking place and provides an opportunity for discussion of its progress and the conclusions reached.

The growing interest in marine parasitology was reflected in two papers by Z. Kabata (Marine Laboratory, Aberdeen) and H. H. Williams (University College of Wales, Cardiff). Dr. Williams had examined a number of elasmobranchs eaught in British fishing areas and recovered the tetraphyllidean cestodes which they contained. A high degree of host-specificity exists in this group, and, although there are still many unidentified species, a very interesting discussion was given of the physiological, ecological and morphological factors which oontribute towards restricting a species to a particular host. Dr. Kabata based his discussion on the parasitological examination of some 500 whiting and haddock and presented some data relating the age of the fish to the parasitic fauna which it supports.

Temperature and climatic conditions have an important influence on the level of helminthic infesta. tion in domestic animals. H. D. Crofton (Bristol) has devised a technique for accurately observing the rate of development of nematode eggs and larvæ from sheep. The data, which he has obtained on the limits of temperature tolerance of different species and the effects of temperature on the rate of development, provided the basis for a useful discussion on the ecology of the parasites in relation to domestic stock. The importance of temperature and moisture-levels on different stages in the life-cycle of Fasciola hepatica was discussed by C. B. Ollerenshaw (Central Veterinary Laboratory, Weybridge), with particular reference to the incidence of fascioliasis in Anglesey. Dr. Ollerenshaw was able to correlate the incidence of the disease in this area, which was particularly high during 1958, with meteorological data obtained during the preceding year.

The significance of the trypanosomatid kinetoplast figured in the discussions by three speakers. J. R. Baker (London School of Hygiene and Tropical Medicine) and K. Vickerman (University College, London), in a joint paper, showed a series of electron micrographs of insect and vertebrate trypanosomatids, and the possible functions of the kinetoplast were reviewed with particular reference to kinetoplastic and akinetoplastic strains and to the life-history of the species studied. When trypanosomes (T. gambiense and $T$. rhodesiense) are exposed to dilute solutions of acriflavine they become photosensitive and are rapidly killed by light. The kinetoplast of the sensitized trypanosome fluoresces intensely in ultra-violet light, but experiments by P. J. Walker (National Institute for Medical Research, Mill Hill) have indicated that this organelle is not the only site of the photosensitivity.

The role of arthropods as vectors of parasitic infections was discussed in the course of three papers. D. S. Bertram and R. G. Bird (London School of Hygiene and Tropical Medicine) described the subcellular morphology of Aedes aegypti with the aid of a series of electromicrographs. This study was particularly concerned with the transmission of Semliki Forest virus, and the presence of virus particles within the cells was correlated with the infectivity of the insects. These workers also sug. gested that the complexity of the membranes surrounding the anopheline ovary reduces the possibility of the transmission of infection through the mosquito egg. In ticks, however, the membrane structure is simpler, and transovarian transmission of parasitic infections therefore can take place more easily. Transmission in this way of Babesia divergens by larvæ of Ixodes ricinus following the feeding of adult ticks on infected calves had been observed by Davies and Joyner in the course of a series of transmission experiments carried out at the Central Veterinary Laboratory, Weybridge. The feeding mechanism by which Ixodes ricinus obtains infected blood was the subject of an investigation by E. Sutton (King's College, London). Histological preparations were shown to illustrate the digestion of the host tissue which takes place around the inserted mouth-parts. Spectrophotometric measurements of the hæmoglobin content of individual ticks indicate that ticks feed on varying amounts of non-blood and blood tissue.

Parasites in relation to natural fauna were also discussed. A. M. Dunn (Veterinary School, Glasgow) has recorded the intestinal helminth parasites of the 
three species of wild deer on Rum in the Inner Hebrides. This paper was notable for some very beautiful illustrations of the habitats. The rigour of a littorine habitat was apparent in the discussion by B. L. James (Aberystwyth) of the development and life-history of Parvatrema homoeotecnum n.sp., a gymnophalline trematode which parasitizes the gastropod molluse, Littorina saxatilis and oyster eatchers. This parasite shows several specialized and primitive features. The perch and pike in Llyn Tejid in Merionethshire are the hosts of a pseudophyllidean cestode, Triaenophorus nodulosus. By taking regular nettings, J. C. Chubb (Liverpool) was able to obtain data relating the incidence and development of the parasite to the growth of the fish. Also following this theme of seasonal incidence, but with quite a different parasite, W. N. Beesley (Weybridge) discussed the development and migration of Hypoderma bovis and $H$. lineatum in domestic cattle.

Work during recent years has shown that parasitology is a fertile field for the application of new laboratory techniques. Thus, cytochemical techniques were used to characterize the functions of the male accessory and reproductive glands of Argas persicus (R. J. Tatchell, Cambridge), and the pseudosuckers and holdfast organ of the trematode Diplostomum phoxini (D. L. Lee, Cambridge). The nutritional requirements of the latter have been the subject of in vitro cultural studies by C. A. Hopkins and M. O. Williams (Glasgow). In the field of immunology, agar diffusion techniques have been applied to such widely differing subjects as Eimeria infections in fowls (M. E. Rose and P. L. Long, Houghton) and schistosomes in monkeys (S. R. Smithers, National Institute for Medical Research). Despite the application of new techniques, parasitology still occasionally requires systematic descriptions, an example of which was the paper by S. T. Fernando (Cambridge) dealing with the developmental stages of Mecistocirrus digitatus, a nematode found in the abomasum of cattle in Ceylon, India and the Far East.

The proceedings of this meeting will not be published in detail. The spring meeting in 1962 is to be held in Cambridge during April 3-5.

L. P. JOYNER

\section{WATER RESOURCES IN WALES}

$\mathrm{L}^{\mathrm{s}}$ ARGELY as a result of the water supply difficulties of 1955 and 1957 , the Minister of Housing and Local Government (who is also Minister for Welsh Affairs) appointed in February 1958 a committee to advise him on the use and conservation of water resources in Wales. The Committee has already expressed interim views in February 1959 on the Milford Haven barrage scheme (which it favoured), and has recently published its first full Report on the Water Resources of Wales*.

This report is a notable advance forward in our knowledge of the Water Resources of Great Britain and in their proper employment. The Minister indicated to the Committee that the most urgent problem was to assess the water resources in relation to foreseeable demand, and three guiding questions were posed: (a) What are the water resources? (b) What is the exploitable surplus ? and (c) How can such surplus best be employed?

The Committee consisted of persons from different parts of Wales with interests in hydrology but not themselves engineers or technical experts. The report, as a result, considers not only the hydrological survey of Wales carried out by the Ministry's engineers in 1957 but also social, economic and cultural aspects of the problems encountered. The hydrological survey (not generally available) gives detailed estimates of the maximum supply of water which could be obtained from Wales on the assumption that hydrological considerations are the sole governing factor. The Committee, however, examined more than 180 suggested reservoir sites in the light of $(a)$ geological structure, $(b)$ agricultural interests, (c) existing communities, (d) amenities, and (e) cost. The sites were then placed in one of four categories: ' $A$ ' sites, to which no objection could be seen; ' $B$ ' sites, where a moderate degree of objection was foreseen; ' $C$ ' sites, development of which could only be envisaged if the need for water in the country as *Welsh Advisory Water Committee. Report on the Water Resources
(London: H.M.S.O., 1961.) 58. net. a whole were to become over-riding; and lastly, sites rejected as completely unsuitable.

As the Committee also considered the various resources in relationship to conventional impounding reservoirs, regulating reservoirs, estuarine reservoirs and direct abstraction, it will be immediately apparent that there is no clear-cut and definite answer to the first question: "What are the water resources of Wales ?". Appendix 8 of the report, however, sets out the various possibilities : these, on the Committee's definition, range from a minimum of 1,195 million gallons a day to a maximum of 2,895 million gallons a day.

These resources are next considered in relationship to the demand for water. Here the Committee has not only considered the present situation but also has looked ahead into the 'foreseeable future'. This has been taken, despite the hazards of extrapolation, as a period of 30 years. For this purpose Wales is divided into five geographical zones-south-west, north-west, north-east, south-east and central. In only one of these zones, the south-east, has the Committee found serious prospective deficiency of water : in all the others there is not only an adequate amount of available water but also an exploitable surplus. Ample allowance has been made in these calculations for a continued expansion in the Welsh economy and for increased demands for water. The Committee estimates that, taken as a whole, the Principality has an exploitable surplus of resources over demand of between 235 and 800 million gallons a day according to the system of development adopted (this is seen in perspective when it is recollected that public undertakings in England and Wales at present supply some 2,400 million gallons a day).

The Committee suggests that that part of the surplus which can be most easily used to supply areas in England which are short of water is to be found in the upper basins of the Severn, Wye and Dee (the 'central zone'). 'This is an area of heavy rainfall and very low population with limited local demands on 